\title{
DISCUSSIONS
}

\section{Numerical analysis of rectangular rafts on layered foundations}

FRASER, R. A. \& WARDLE, L. J. (1976). Géotechnique 26, No. 4, 613-630.

\section{A. Wood, Department of Civil Engineering, Queen Mary College, London}

The use of numerical techniques for the analysis of rectangular raft foundations is now well established. With few exceptions the raft and any superstructure are modelled using an assemblage of the appropriate elastic finite elements. A convenient soil model is that of a layered elastic continuum the surface displacement of which may be related to the initially unknown ground reactions using the rather unwieldy complete three-dimensional finite element representation or the more direct approach used by the Authors. A third less exact but perhaps more versatile approach is that used in conventional design. Namcly, that the stress distribution within the layered continuum may be approximated to that within a homogeneous, half-space; and that the inhomogeneity need only be considered in evaluating the strains and hence the surface displacements. The latter approach has been developed extensively over several years with reference to behaviour of raft foundations and skeletal frame structures supported on pad footings using both elastic and time-dependent consolidation models for the soil (Larnach and Wood, 1972; Wood and Larnach, 1974, 1975). Encouraging agreement has also been obtained between computed and measured settlements in the back-analysis of several structures for which good performance records were available (Ilooper and Wood, 1976; Wood, Larnach and Woodman, 1977). The approach has several advantages over more precise elastic models in that inelastic stress-strain relationships may be easily incorporated. The model is one the practising engineer already has a feel for, and computing costs (in terms of central processor time and storage) are generally significantly less than those required by the more exact formulations.

In order to illustrate the validity of the homogeneous half-space approximation, results are presented in Table 1 for the numerical example used by the Authors.

It will be apparent that although the central settlement is underestimated by $15 \%$, exact agreement has been obtained for the differential settlement and maximum moment. Such agreement may be somewhat fortuitous but is nevertheless very encouraging.

When considering the all important relative raft-soil stiffness, $K$, the Authors have used a factor incorporating the width of the raft but not the length. I would suggest that a more general expression for this factor should be of the form

$$
K=\frac{E_{\mathrm{r}}\left(1-\nu_{\mathrm{s}}{ }^{2}\right)}{E_{\mathrm{s}}\left(1-\nu_{\mathrm{r}}^{2}\right)}\left(\frac{t}{\sqrt{a b}}\right)^{3}
$$

where $a$ and $b$ are the two characteristic dimensions of the rectangle and $t$ is the raft thickness. Such a formulation might then lead to a standard expression for $K$.

Finally it should be stressed that in the design of raft foundations the evaluation of the bending moments and the associated deformations are only part of the story, in my own

Table 1

\begin{tabular}{l|l|c}
\hline & \multicolumn{1}{|c|}{ Exact } & Half-space approximation \\
\hline Central settlement & $0.0114 \mathrm{~m}$ & $0.0097 \mathrm{~m}$ \\
Differential settlement & $0.0027 \mathrm{~m}$ & $0.0027 \mathrm{~m}$ \\
Maximum moment & $0.044 \mathrm{MN} \mathrm{m} / \mathrm{m}$ & $0.044 \mathrm{MN} \mathrm{m} / \mathrm{m}$ \\
\hline
\end{tabular}


experience the thickness of the raft has been more strongly influenced by the consideration of shear.

\section{ACKNOWLEDGEMENT}

The computed results were obtained using the facilities of the University of London Computer Centre.

\section{REFERENCES}

Hooper, J. A. \& Wood, L. A. (1976). Foundation analysis of a cross-wall structure. Performance of Building Structures. Pentech Press.

Larnach, W. J. \& Wood, L. A. (1972). The effect of soil-structure interaction on settlements. Proc. Int. Symp. Computer-Aided Structural Design. Department of Engineering, Warwick University.

Wood, L. A. \& Larnach, W. J. (1974). The effects of soil-structure interaction on raft foundations. Settlement of Structures. Pentech Press.

Wood, L. A. \& Larnach, W. J. (1975). The interactive behaviour of a soil-structure system and its effect on settlements. Symp. Geot. Struct. University of New South Wales.

Wood, L. A., Larnach, W. J. \& Woodman, N. J. (1977). Observed and computed settlements of two buildings. Proc. Int. Symp. Soil-Structure Interaction. University Roorkee.

\section{Lateral displacement of shallow buried pipelines due to adjacent deep trench excavations}

CROFTS, J. E., MENZIES, B. K. \& TARZI, A. I. (1977). Géotechnique 27, No. 2, 161-179.

\section{F. Symons, Transport and Road Research Laboratory*}

In this Paper an approach is suggested for estimating the risk of pipe fracture due to the excavation and backfilling of a trench parallel to a pipeline. In view of the wide interest this is likely to attract in both investigations of failure and the assessment of proposed works, it is useful to examine the implications of adopting the method and the influence on the results of some of the variables involved.

The locations of the trench relative to a pipeline encompassed by each risk category can be determined by specifying the required strain in equations (12) and (13) of the Paper and expressing the components of pipe movement in terms of the $\alpha$ values. By doing this the distances between a $5 \mathrm{~m}$ deep trench and a $0.286 \mathrm{~m}$ external diameter spun iron pipeline within which the short term risk of breakage or unserviceability is unacceptable (Category 3 ) have been calculated. The results are given in Table 1 for natural clay soils with a range of stiffnesses. The first column of the Table applies to the conditions given in the worked example of Appendix 1 of the Paper. The second column gives results when the component of pipe movement $x_{2}$ has been increased to the suggested maximum value of $28 \mathrm{~mm}$. The third column considers these same conditions but with the suggested reduction applied to the component of pipe movement $x_{3}$ to take account of restraint from a thicker road surface. The dominant effect of soil stiffness on the results is clearly shown; the extent of the zone of risk given by the method increasing with soil stiffness. Examination of the calculations indicates however that although pipe movements are somewhat greater in soft than stiff clay at comparable distances from the trench, this is more than offset by the effect of soil stiffness in the determination of pipe strain.

For the stiffer clay soils frequently encountered in urban areas, the results indicate that application of the proposed method of risk assessment could effectively preclude the construction of trenches within a considerable distance of an existing pipeline. Moreover for cast iron

* Crown copyright. The views expressed in this Discussion are not necessarily those of the Department of the Environment or of the Department of Transport. 